Téoros

Revue de recherche en tourisme

\title{
Capitales culturelles de l'Europe - Antwerpen 93
}

\section{André Hut}

Volume 12, numéro 1, mars 1993

Québec, capitale et région touristiques

URI : https://id.erudit.org/iderudit/1078206ar

DOI : https://doi.org/10.7202/1078206ar

Aller au sommaire du numéro

Éditeur(s)

Université du Québec à Montréal

ISSN

0712-8657 (imprimé)

1923-2705 (numérique)

Découvrir la revue

Citer cet article

Hut, A. (1993). Capitales culturelles de l'Europe - Antwerpen 93. Téoros, 12(1),

53-55. https://doi.org/10.7202/1078206ar d'utilisation que vous pouvez consulter en ligne.

https://apropos.erudit.org/fr/usagers/politique-dutilisation/ 


\title{
Capitales culturelles de I'Europe - Antwerpen 93
}

\author{
André Hut"
}

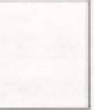

Un des fondateurs de la Communauté Européenne affimmait récemment que, s'il fallait, à nouveau, construire l'Europe, il commencerait non plus avec l"6oonomie mais avec laCULTURE. Il auraitplutôt dûdire les cultures!

\section{Affrontements culturels}

Les Nord-Américains ne s"étonnent-ils pas, après quelques centaines de kilomètres parcourus en Europe, d'être arrêtés par une frontière, de devoir présenter un passeportou le certificat d'immatriculation de la voiture, ou changer de monnaie, de langue, de traditions culinaires et de boisson nationale, de dormir dans un lit dressé d"une autre façon...

Ils découvrent, d'une manière concrète et quotidienne, l'extraordinaire résistance culturelle que les autochtones ont opposée au pouvoir occupant la région, successivement par conquête, annexion, alliance matrimoniale ou politique, héritage ou contrepartie lors des négociations entre belligérants à l'occasion des Traités de victoire ou de paix. Les grands empires - grec ou romain, nusse ou ottoman, germanique ou austro-hongrois, arabe, espagnol ou français - ont colonisé, économiquement et culturellement, des populations bien différentes des leurs. Les conquérants respectifs n'ont pas hésité à piller, entr'autres choses, les tableaux et les livres précieux, les oeuvres d'art et les bijoux, au point qu'il faut aller dans les musées étrangers pour voir et découvrir les célèbres peintres de son propre pays: l'école flamande par exemple. La célébration du cinqcentième anniversaire de la découverte des Amériques et les revendications des pays récemment décolonisés manifestent les habitudes acquises d'enrichir les musćes de Londres, Paris, Bruxelles ou Berlin, des trésors culturels des pays conquis.

Parallelement, les cours royales et impériales ont accueilli et entretenu, pour leur plaisir et leur prestige, des architectes, artistes peintres ou musiciens, hommes de sciences. Si ce

Monsieur André Hut est, de la Belgique, le correspondant regulier de Thoros pour l'Europe. mécénat a permis de vivre et de produire culturellement des chefs d'oeuvres à des personnes talentueuses issues de la diversite culturelle, souvent minoriste, de leurs provinces propres, annexées ou étrangères, il a consisté, en même temps, à les acheter et se les approprier.

L'histoire des pays européens, de l'Espagne à l'Arménie, se caractérise, en outre, par des purificationsethniques perpétrées déjà - bien avant les Nazis, les Serbes ou les ex-Répu= bliquesSoviétiques-pardéplacements, exils, exterminations, interdictions de parler la langue locale, fermeture ou destruction des lieux de culte, conversions forcées et inquisitioneoclésiastique, persécutions religieuses et pogroms.

En effet, une série d'événements ont compromis l'unité des citoyens de l'Europe, notamment: la séparation entre l'empire de Byzance orthodoxe et l'empire latin d'occident, la réforme protestante et la riposte féroce de la contre-réforme catholique, la présence des Arabes durant plusieurs siecles dans la péninsule ibérique refoulée par la reconquista espagnole, les croisades chretiennes contre l'invasion ottomane dans le Sud-Est du continent. Ces guerres de religion entre chrétiens ou fils d'Abraham ont provoqué chez les citoyens de la maison commune des césures plus profondes que les frontières, laissé des cicatrices indélébiles nourrissant des haines farouches et des rancunes tenaces, entretenu des incompréhensions viscérales.

Cela explique l'irrationalité passionnelle, à première vue, des luttes fratricides des catholiques et des protestants d'Irlande, des Bosniaques serbes, croates et musulmans...

Au fur et à mesure de la chute ou de la ruine des royautés omnipotentes, de l'implosion des dictatures bourgeoises de l'Ouest ou prolétariennes de l'Est, du développement de l'enseignement et de l'éducation dans les États modernes et démocratiques... $s^{\text {'affir- }}$ ment, d'une manière pacifique ou violente, les revendications ethniques, culturelles ou religieuses des populations dominees par la culture dominante: basques ou irlandais, slovaques et tchèques, flamands et wallons, bretons et occitans, serbes orthodoxes et croates catholiques...

Les rois et les États ont dû progressivement remettre en cause la déclaration et la prise de conscience des Droits de l'homme aidant leurs pratiques centralisatrices et tenir compte des volontés d'auto-gestion économique et culturelle des populations très diversifiées, rassemblées historiquement et artificiellement, à leur corps défendant souvent, sous une juridiction unique: les uns par la décentralisation à la française, les autres par un processus de fédéralisation à la belge ou la reconnaissance d'une certaine autonomie de provinces espagnoles, italiennes et autres Kosovo.

Ilétait nécessaire d'énoncer les diverses clefs qui permettent de clarifier - outre les causes économiques - les différentes raisons culturelles qui sont à l'origine des éclatements et affrontements, explicités ci-dessus, et qui perdurent sournoisement dans les mentalités populaires.

La compréhension entre les peuples que pourrait favoriser le tourisme culturel, ne va pas de soi: elle exige information, prise de conscience, apprentissage, conversion des mentalités et des pratiques.

On comprend que les ministres des Affaires culturelles de la trentaine de pays rassemblés dans le Conseil del'Europeaient pris comme thème de leur conférence de 1990 à Palerme La société multiculturelle: un défi pour les politiques culturelles. Ils ont reconnu que, face aux divisions et aux affrontements mentionnés plus haut, al'unité de la culture européenne se caractérise et s'exprime par un ensemble d'ideaux et de valeurs sur le plan éthique et religieux, politique et juridique, artistiqueet scientifique, quis'enracinent dans son histoire et qui constituent une contribution essentielle au patrimoine de l'humanites.

Ces ministres ont proclamé solennellement la déclaration: Société multiculturelle et identité culturelle européenne. Celle-ci répond à une urgence et propose wles initiati- 
ves, moyens et méthodes visant à promouvoir le dialogue et les échanges entre les cultures, notamment par la mise en valeur des cultures minoritaires basće sur le droit à la différence et reconnue légitimement par les autres dans leur spécificité et leur identité propres ${ }^{(1)}$.

\section{Capitales culturelles}

Justement, la Communauté Économique Europeenne (CEE), prend une initiative qui va dans le sens de la Déclaration du Conseil de l'Europe. Quelle est son origine? Quels objectifs poursuit-elle? Quelle évaluation peut-on dresser des réalisations passées? Enfin, quel programme envisage la ville d'Antwerpen, Anvers, capitale culturelle pour 1993? En répondant à ces questions, on pensera à la ville de Québec qui se présente comme une capitale culturelle en Amérique du Nord.

\section{Origine}

C'est madame Mélina Mercouri, ministre grec de la Culture qui lança l'idée et le Conseil des ministres du 5 juin 1985 , avecses collègues, décida de désigner annuellement une villed'Europe comme capitale culturelle. II s'agissait de rendre un hommage à la richesse et la diversité de la culture europeenne.

\section{Objectifs}

Le but consiste toujours à rapprocher des États membres et a favoriser la collaboration culturelle entre ceux-ci. Deux objectifs entrent en ligne de compte: rendre la culture de la ville ou de la région plus accessible à un public européen, voire international, enmême temps que de donner une vitrine a l'actualite culturelle européenne.

\section{Évaluation des prédécesseurs}

Laissons à l'auteur du document présentant le projet d'Antwerpen 93 la propriété de l'évaluation nécessairement subjective des précedentes réalisations.

"Chacune des villes élues jusqu'à présent a interprété le projet selon son propre goât, sa propre sensibilite. Depuis 1985, huit villes ontété à l'honneur: Athènes(1985), Florence (1986). Amsterdam (1987), Berlin (1988). Paris (1989), Glasgow (1990), Dublin (1991) et Madrid (1992). Athenes et Florence ont essuyé les plâtres, organisant des festivals d'ans modestes, axés sur l'aniquité et le classicisme. Amsterdam et Berlin, traditionnellement des podiums importants de la culture internationale, placerent le festival sous le signe des arts rénovés. Les deux villes avaient opte pour un festival unique, ce qui limitait les effets a long terme. A Paris, les activités dans le cadre de la capitale culturelle coinciderent avec le Bicentenaire, dont les manifestations somptueuses éclipsèrent quelque peu l'idée de ville européenne. La première non-capitale, Glasgow, n'était pas davantage une ville d'ari notoire. La métropole ecossaise trai"nait l'image d'une ville industrielle paupérisée. Les autorités résenèrent un budget sans précédent, afin de raviver le prestige international et la confiance en soi de Glasgow. Et on ne laissa pas passer l'occasion. Au bout du compte, le projet ne se limita pas à la seule culture. C'est ainsi que fut réalisée une nowvelle infrastructure qui profitera encore longtemps a cette cité industrielle, autrefois réputée pour sa grise mine. Soudain, tout devenait possible dans cette ville en éclosion. Dublin opta pour la même approche globale, füt-ce d̀ plus petite échelle. Néanmoins, Dublin réussit en tant que capitale culturelle à budget réduit à réaliser d'incroyables transformations urbanistiques et à rallumer les projecteurs sur la tradition litteraire irlandaise. En 1992, l'ambitieuse Madrid prend le relais. En cette année espagnole par excellence, la fiere capitale ne pouvait manquer aux côtés de Barcelone et de Seville. Madrid woit très grand: travaux d'infrastructure, restaurations, nouveaux musées et théâtres, reamenagement des parcs. Madrid s'interesse néanmoins à d'autres capitales culturelles. Anvers apparaîtra dans une exposition qui se tient dans un ravissant château d'eau. Le tour d'horizon des États membres europeens connaitra son ultime étape en 1996. Après Antwerpen 93 suivent encore Lisbonne (1994). Luxembourg (1995) et Copenhague $(1996)$, $^{(2)}$

\section{Antwerpen 93}

Relevons dans le copieux et fastueux programme les éléments qui refletent l'identité de la ville. Eneffet, aAnvers doitsaréputation universelle au fait d'être une ville portuaire, une ville de commerce et le centre mondial de l'industrie du diamant. Mais Anvers est aussi une ville d'art... avec un grand passé culturel, qui bourdonne [aujourd'hui] d"activités artistiquess ${ }^{\text {क) }}$.

Pour le passé, le fil conducteur sera l'exposition: «Anvers, histoire d'une métropole" pour découvrir que lacélébritéd'Anvers date des $\mathrm{XVI}^{\circ}$ et $\mathrm{XVII}^{\circ}$ siecles: la ville se métamorphosa en quelques années en un centre mondial de culture, de commerce et de finance. Cette prospérité grandissante attirait beaucoup de négociants étrangers et bien desentreprises intemationales y implantèrent une filiale.

"Mais, durant la dewième moineé du XVI siècle, Anvers se trouva au coeur d'un conflit politico-religieux international... La guerre entre les Pays-Bas et l'Espagne, qui fut celle des catholiques contre les protestants, aboutit en 1585 à la chute d'Anvers! Penseurs et commerçants s'enfuirent vers les provinces du Nord. Anvers devint un bastion du catholicisme. Mais la machine à propagande, mise en route par le Concile de Trente, continua à promowvoir les arts. L'église baroque et sa façade imposante - tant au figuré qu'à la lettre - fut une des armes maîtresses de la contre-réforme. L'économie d'Anvers dans cette période reposait essentiellement sur l'exportation de produits de luxe vers tous les coins du monde, ${ }^{(4)}$

Complétant le panorama, une exposition sur la «Botaniquedans les Pays-Bas méridionaux (1500-1650)p, au musée Plantin-Morétus, révèle la dimension scientifique et, déjà, l'intérêt pour la nature.

"L'Anvers du XVT siecle - en particulier l'imprimerie de Plantin - était un vivier humaniste. Parallelement... se développa l'intérêt pour les sciences exactes. Pour cette raison, Christophe Plantin publia les oeuvres des botanistes les plus renomines de son temps. La science botanique doit une fiere chandelle à des Flamands comme Dodoens (dit Dodonaeus), de l'Escluse (dit Clusius, né à Arras), Lobelius, ainsi qu'au pharmacien-botaniste anversois Pieter van Coudenberghe. Aussil'exposition ne manquera pas d'insister sur l'influence exercée par les ouvrages de botanique édités chez Plantin sur les développenents internationaux de cette science jusqu'en 1650. Christophe Plantin était également un passionné de plantes: et les botanistes d'aujourd'hui le considerent conme un de leurs principaux précurseurs, $y^{(5)}$

Quant au volet artistique, le quatrecentième anniversaire de la naissance de Jacob Jordaens offre l'occasion de rassembler l'ocuvre de ce célebre peintre anversois dans une grandiose exposition. Elle cumule à nouveau les dimensions culturelles, religieuses et europeennes. 
"Fils d'un marchand de toiles de lin, né à Anvers en 1593, il commença son apprentissage à l'âge de quatorze ans chez Adam van Noort, dont il epouserait la fille Catharina neuf ans plus tard. Elle lui fit connaitre le calvinisme, une conviction religieuse qu'il mettrait, plus tard, fort à l'avant-plan dans son oeuvre. Le style pictural de Jordaensfut principalement influencé par son concitoyen Pierre Paul Rubens. Bien qu'tl ne fut pas apprenti chez Rubens, il connaissait néanmoins très bien son travail. [...] Dans l'oeuvre de Jacob Jordaens, qui connut sa grande percée en 1630 , on retrouve souvent les mêmes thèmes qui caractérisent sa personnalité. Il s'agit en général de tableaux moralisateurs inspirés des proverbes ou pensées de Jacob Cats. Après la disparition de Rubens (1640) et de Van Dyck (1641), Jordaens fut sacré maître à penser des peintres des Pays-Bas méridionaux. Ceci donna lieu a des commandes prestigieuses. C'estainsiqu'iltermina pour le roid'Espagne quelques toiles restées inachevées dans l'atelier de Rubens. Amalia Van Solms, la veuve de Frédéric-HenrideNassau, luidonna commission de peindre, avec d'autres mâttresflamands et hollandais, un énormedecor pour la Maison ten Bosch d La Haye, ${ }^{(6)}$

Quant à la période moderne, c'est l'épopée coloniale qui relancera le port et la ville d'Anvers à l'avant-plan. Outre l'Institut de médecine tropicale et le musée d'ethnographique, le jardin zoologique, qui jouxte la gare centrale, remarquablement rénovée, compte parmi les plus anciens du monde.

"L'exposition "I50 ans de Zoo et son patrimoine artistique" retrace l'histoire du Zoo, son developpement et son essor, évoquera les liens avec la population anversoise, montrera les grandes réalisations, les animauxet la collection propre, abordera les arts et les sciences, la protection de la nature, etc., $\%$

Enfin, après les villes mondiales comme Londres (1851), Paris (1867), Vienne (1873), ce fut le tour d'Anvers, en 1885, d' organiser pour la première fois une Exposition Universelle, prouesse qu'elle réćditera en 1894 et 1930.

¿Les expositions universelles prétendaient offrir un panorama de toutes les activités humaines. La production artistique n'en était qu'une facette. Ces "World Fairs" étaient de gigantesques manifestations qui s'échelonnaient sur plusieurs mois et attiraient des millions de visiteurs. En tant qu'elément exponentiel de la société industrielle, ces expositions mettaient surtout l'accent sur les nouveaux produits et techniqueset sur lesterritoirescoloniauxconquis récemment. Les expos baignaient dans un discours optimiste, qui attestait de la confiance inconditionnelle dans le progrès. Pour les pays organisateurs elles étaient aussi l'expression du prestige national. "Le rêve panoramique" - exposition des expositions - esquissera une image de la périade 18851930. Il présentera une portion d'histoire des mentalités, où l'on retrouvera la foi de l'Occident en sa souveraineté universelle ainsi qu'en l'éternel progrès. Cette foi ne differe guère du rêve anversois de revivre un Siècle d'Or comme "Métropole de l'Occident, ${ }^{(8)}$

Mentionnons, pour terminer, que c'est la communauté juive d'Anvers, la plus importante du Royaume, qui accueilla, en 1492, un grand nombre de frères juifs expulsés d'Espagne par Isabelle de Castille avant de subir, a son tour, la persécution nazie et l'extermination. Plusquejamais, sa présence est particulièrement repérable notamment au Centre mondial du diamant qu'elle anime et qui présente un programme particulièrement brillant. $f$

\section{NOTES ET RÉFÉRENCES}

(1) Ge Contérence des ministres européens responsables des Affaires culturelles - Palerme (Italie). 25-26 avril 1990. CMC (90) 6-Conseil de l'EuropeStrasbourg; la Déclaration, page 6, 2.2.

(2) Document Qu'est-ce qui est beau, qu'est-ce qui est laid, Antwerpen 90, capitale culturelle de rEurope, projet, Premier Magazina, juin 1992. page 7 .

(3) Brochure Where Culture is Capital, p. 2.

(4) Document: Qu'estce qui est beau, op, cit, p.9.

(5) Idem, p. 10.

(6) Idem, p. 12

(7) Idem, p. 39

(8) Idem, p. 12. Secrétariat Antwerpen 93, Grote Marlat 29, B.2000 Antwerpon. Fax: 32.32.26.15.66 